\title{
SIMPLE AND EFFICIENT ACCESS TO \\ PYRAZINE-2,5- AND -2,6-DICARBALDEHYDES
}

Radek Coufal, ${ }^{* 1,2}$ Markéta Prusková,, ${ }^{1,2}$ Ivana Císařová, ${ }^{3}$ Dušan Drahoňovský, ${ }^{2, \dagger}$ Jiř́ Vohlídal*1 $^{* 1}$

${ }^{1}$ Charles University in Prague, Faculty of Science, Department of Physical and Macromolecular Chemistry, Hlavova 8/2030, 12840 Prague 2, Czech Republic

${ }^{2}$ Charles University in Prague, Faculty of Science, Department of Organic Chemistry, Hlavova 8/2030, 12840 Prague 2, Czech Republic

${ }^{3}$ Charles University in Prague, Faculty of Science, Department of Inorganic Chemistry, Hlavova 8/2030, 12840 Prague 2, Czech Republic

E-mail: coufalr@natur.cuni.cz; vohlidal@natur.cuni.cz

${ }^{\dagger}$ Unfortunately, already no among us.

\section{Supporting Information}

\author{
Experimental procedures \\ Copies of NMR, IR and Raman spectra \\ X-Ray structure data
}




\section{EXPERIMENTAL}

Measurements. NMR spectra were recorded on Varian SYSTEM 300 and Bruker Avance-III 600 instruments and referenced to residual solvent signal. IR spectra were recorded on Nicolet Avatar 370 FT-IR and Thermo Nicolet 7600 FTIR spectrometer equipped with a Spectra Tech InspectIR Plus microscopic accessory using KBr-diluted samples and diffuse reflectance technique (DRIFT) (128 or more scans at resolution $4 \mathrm{~cm}^{-1}$ ). Raman spectra of solid samples were recorded on a DXR Raman microscope (Thermo Scientific) using excitations at 532 and $780 \mathrm{~nm}$ and the laser power at sample from 2 to $5 \mathrm{~mW}$. Mass spectra were recorded with Q-Tof micro (Waters) instrument. Crystallographic data for aldehydes 1, 2 and dihydropyrazine 11 were collected on Nonius Kappa CCD diffractometer equipped with Bruker APEX-II CCD detector, using monochromatic MoKa radiation $(\lambda=0.71073 \AA)$. The structures were solved by direct methods (SHELXS) $)^{[1]}$ and refined by full matrix least squares based on $F^{2}$ (SHELXL97). ${ }^{[1]}$ The hydrogen atoms on carbon were fixed into idealized positions (riding model) and assigned temperature factors either $H_{\text {iso }}(\mathrm{H})=1.2 U_{\text {eq }}$ (pivot atom) or $H_{\text {iso }}(\mathrm{H})=1.5 U_{\text {eq }}$ for methyl moiety. Melting points were measured on Büchi Melting Point B-545 ( $\left.\pm 0.2{ }^{\circ} \mathrm{C}\right)$.

Materials. Solvents were dried by standard procedures. Silica gel (Merck, 0.040-0.063 mm) was used for column chromatography. A radial-layer chromatograph (Chromatotron) was used for purification of crude products as well. All starting compounds, reagents and solvents were purchased from commercial suppliers. Anhydrous zinc chloride was dried using thionyl chloride $^{[2]}$ Dimethyl pyrazine-2,5-dicarboxylate, ${ }^{[3]}$ 2,5-bis(chloromethyl)pyrazine ${ }^{[4]}$ and $N, N, N^{\prime}, N^{\prime}$-tetramethyl(benzene-1,2-diamine)- $N$-oxide ${ }^{[5]}$ were prepared according to the published protocols. Dimethyl pyrazine-2,6-dicarboxylate was prepared by adopting the literature protocol for 2,5-isomer. Both dimethyl pyrazinedicarboxylates were purified by recrystallization/vacuum sublimation (white solids) for further use. 
Methyl 5-(hydroxymethyl)pyrazine-2-carboxylate (6). Sodium borohydride (18.0 mg, $0.48 \mathrm{mmol}$ ) was stepwise added to a stirred suspension of dimethyl pyrazine-2,5dicarboxylate $(89.8 \mathrm{mg}, 0.46 \mathrm{mmol})$ in a dry $7: 3$ mixture of $\mathrm{MeOH} / \mathrm{DCM}(5 \mathrm{~mL})$ at $0{ }^{\circ} \mathrm{C}$. The resulting yellow reaction mixture was stirred for $1.5 \mathrm{~h}$ and then the additional portion of sodium borohydride (17.9 mg, $0.46 \mathrm{mmol}$ ) was added. The TLC analysis (silica/ethyl acetate) made after next 30 min revealed almost complete consumption of the starting material. The reaction was quenched with a saturated aqueous solution of $\mathrm{NH}_{4} \mathrm{Cl}(5 \mathrm{~mL})$, the obtained mixture was diluted with chloroform $(10 \mathrm{~mL})$ and the aqueous and organic layers were separated. Aqueous phase was extracted with chloroform $(3 \times 10 \mathrm{~mL})$, DCM $(1 \times 10 \mathrm{~mL})$ and ethyl acetate $(1 \times 10 \mathrm{~mL})$. The combined organic layers were dried with $\mathrm{MgSO}_{4}(4.5 \mathrm{~g})$ and the solvents were removed under reduced pressure. Crude product was dissolved in a small volume of the starting mobile phase (hexane/EtOAc, 1:1 by vol.) with a few added drops of chloroform and $\mathrm{MeOH}$ and purified by the gradient TLC chromatography (final mobile phase hexane/EtOAc 1:3) to give the product as a brownish solid ( 96\% purity) in the preparative yield of $71 \%$ (54.4 mg). M.p. $81.8{ }^{\circ} \mathrm{C} .{ }^{1} \mathrm{HNMR}\left(\mathrm{CDCl}_{3}, 600.17 \mathrm{MHz}\right): 9.25(\mathrm{~s}, 1 \mathrm{H}$, pzCHCCOOMe), 8.78 (s, 1H, pzCHCCH$\left.{ }_{2} \mathrm{OH}\right), 4.95$ (s, 2H, $\left.\mathrm{CH}_{2} \mathrm{OH}\right), 4.04$ (s, 3H, $\mathrm{CH}_{3}$ ) ppm. ${ }^{13} \mathrm{C} N M R \quad\left(\mathrm{CDCl}_{3}, \quad 150.91 \mathrm{MHz}\right): \quad 164.5 \quad$ (COOMe), $\quad 158.6 \quad\left(\mathrm{pzCCH}_{2} \mathrm{OH}\right), \quad 145.1$ (pzCHCCOOMe), 142.5 (pzCHCCH$\left.{ }_{2} \mathrm{OH}\right), 142.2$ (pzCCOOMe) $63.2\left(\mathrm{CH}_{2} \mathrm{OH}\right), 53.4\left(\mathrm{CH}_{3}\right)$ ppm. HRMS (APCI): found 169.0609, calcd for $\mathrm{C}_{7} \mathrm{H}_{9} \mathrm{~N}_{2} \mathrm{O}_{3}\left([\mathrm{M}+\mathrm{H}]^{+}\right): 169.0613$. IR $\left(\mathrm{cm}^{-1}\right)$ : 3354 (b), 3234 (b), 3090 (vw), 3063 (vw), 3025 (vw), 2959 (vw), 2935 (vw), $2884(v w), 2848$ (vw), 2821 (vw), 1736 (vs), 1727 (s), $1715(\mathrm{~m}), 1577(\mathrm{w}), 1535$ (w), $1488(\mathrm{w}), 1437(\mathrm{~m}), 1380$ (w), $1344(\mathrm{~m}), 1305(\mathrm{~s}), 1275(\mathrm{~m}), 1239(\mathrm{w}), 1195(\mathrm{~m}), 1174(\mathrm{~m}), 1138(\mathrm{~s}), 1069(\mathrm{~m}), 1033$ (m), $955(w), 809(w), 788(w), 725(w), 411(m)$. Compound 6 was earlier prepared by the different procedure and to our best knowledge, only its ${ }^{1} \mathrm{H}$ NMR spectrum has been reported. ${ }^{[6]}$

Dimethyl 3,4-dihydropyrazine-2,6-dicarboxylate (11). A suspension of ester 10 (238.1 mg; $1.2 \mathrm{mmol})$ in $\mathrm{MeOH}(10 \mathrm{~mL})$ was cooled to ca. $0{ }^{\circ} \mathrm{C}$ under argon atmosphere and then 
sodium borohydride (111.8 $\mathrm{mg} ; 2.9 \mathrm{mmol})$ was slowly added over a period of $30 \mathrm{~min}$, when the reaction mixture turned bright orange. The reaction mixture was stirred at $0{ }^{\circ} \mathrm{C}$ for $90 \mathrm{~min}$ and then the reaction was quenched with saturated aqueous $\mathrm{NH}_{4} \mathrm{Cl}(5 \mathrm{~mL})$. The resulting mixture was extracted with $\mathrm{DCM}(5 \times 20 \mathrm{~mL})$, organic layers were collected, dried over $\mathrm{MgSO}_{4}$ and concentrated in vacuum to dryness to afford the product as a bright orange solid in the isolated yield of $93 \%(222.9 \mathrm{mg})$. The crude product was recrystallized from $\mathrm{MeOH}$ (27 mL). M.p. $184.3{ }^{\circ} \mathrm{C} .{ }^{1} \mathrm{H}$ NMR (600.17 MHz, DMSO-d6): 8.24 (bs, $\left.1 \mathrm{H}, \mathrm{NH}\right), 7.51$ (d, $1 \mathrm{H}$, $\mathrm{CH},{ }^{3} \mathrm{~J}=6.6 \mathrm{~Hz}$ ), 3.96 (d, 2H, CH${ }_{2},{ }^{3} \mathrm{~J}=1.2 \mathrm{~Hz}$ ), 3.73 (s, 3H, $\left.\mathrm{H}_{3} \mathrm{C}-\mathrm{OOC}-\mathrm{C}-\mathrm{CH}_{2}\right), 3.64(\mathrm{~s}, 3 \mathrm{H}$, $\left.\mathbf{H}_{3} \mathrm{C}-\mathrm{OOC}-\mathrm{C}=\mathrm{CH}\right)$ ppm. ${ }^{13} \mathrm{C}$ NMR (150.91 MHz, DMSO-d6): $164.8(\mathbf{C O}-\mathrm{C}=\mathrm{CH}), 163.8$ (CO-C$\left.\mathrm{CH}_{2}\right), 140.6(\mathrm{CH}), 129.4\left(\mathrm{CO}-\mathrm{C}-\mathrm{CH}_{2}\right), 114.4(\mathrm{CO}-\mathrm{C}=\mathrm{CH}), 51.9\left(\mathrm{H}_{3} \mathrm{C}-\mathrm{OOC}-\mathrm{C}-\mathrm{CH}_{2}\right), 50.4\left(\mathrm{H}_{3} \mathbf{C}-\right.$ OOC-C=CH), $38.3\left(\mathrm{CH}_{2}\right)$ ppm. HRMS (APCI): found 197.0559, calcd for $\mathrm{C}_{8} \mathrm{H}_{9} \mathrm{~N}_{2} \mathrm{O}_{4}\left([\mathrm{M}-\mathrm{H}]^{+}\right)$: 197.0562. IR ( $\left.\mathrm{cm}^{-1}\right): 3272(\mathrm{~m}), 3136(\mathrm{vw}), 3031(\mathrm{vw}), 3015(\mathrm{vw}), 2984(\mathrm{vw}), 2949(\mathrm{w}), 1701$ (s), 1679 (s), 1622 (w), $1568(w), 1518$ (w), $1442(m), 1356(m), 1306$ (w), 1261 (vs), 1233 (s), $995(\mathrm{~m}), 742(\mathrm{w})$. The obtained data are in accordance with those published in the literature ${ }^{[7]}$ where this compound was prepared by the different procedure.

2,5-(E,E)-Distyrylpyrazine (12). A mixture of 2,5-dimethylpyrazine $(2.01 \mathrm{~g} ; 18.2 \mathrm{mmol})$, benzaldehyde $(8 \mathrm{~mL})$, and benzoic anhydride (9.99 g; $42 \mathrm{mmol})$ was heated to $175^{\circ} \mathrm{C}$ and stirred under argon atmosphere for 4 days. After cooling to r. t., the solidified mixture was suspended in ethanol $(20 \mathrm{~mL})$. The solid was filtered, properly washed with ethanol $(7 \times 20 \mathrm{~mL})$ and dried in vacuo to give the product $(3.68 \mathrm{~g} ; 70 \%)$ as a fine bright yellow crystalline solid. M.p. $224.2{ }^{\circ} \mathrm{C}$ (lit. ${ }^{[8]}$ m.p. $223-224{ }^{\circ} \mathrm{C}$ ). ${ }^{1} \mathrm{H}$ NMR $\left(299.94 \mathrm{MHz}, \mathrm{CDCl}_{3}\right): 8.60$ (s, 2H, pz), $7.74\left(\mathrm{~d}, 2 \mathrm{H},{ }^{3} \mathrm{~J}=16 \mathrm{~Hz}\right), 7.65-7.57(\mathrm{~m}, 4 \mathrm{H}, \mathrm{Ph}), 7.45-7.30(\mathrm{~m}, 6 \mathrm{H}, \mathrm{Ph}), 7.19$ (d, $2 \mathrm{H},{ }^{3} \mathrm{~J}=16 \mathrm{~Hz}$ ) ppm. The IR and Raman spectra are enclosed below.

2,6-(E,E)-Distyrylpyrazine (13). A mixture of 2,6-dimethylpyrazine $(2.00 \mathrm{~g} ; 18.5 \mathrm{mmol})$, anhydrous $\mathrm{ZnCl}_{2}^{[2]}(2.67 \mathrm{~g} ; 19.6 \mathrm{mmol})$ and benzaldehyde $(29 \mathrm{~mL})$ was heated to $155{ }^{\circ} \mathrm{C}$ for $20 \mathrm{~h}$ with sttiring. Then ethanol $(30 \mathrm{~mL})$ was added and the mixture was kept under reflux for 
ca. 30 min. After cooling to r. t., the precipitated product was collected by filtration, properly washed with ethanol $(4 \times 40 \mathrm{~mL})$ and dried under vacuum to afford the product as a yellow microcrystalline solid in the isolated yield of $81 \%(4.26 \mathrm{~g}) .{ }^{1} \mathrm{H} \mathrm{NMR}\left(299.94 \mathrm{MHz}, \mathrm{CDCl}_{3}\right)$ : $8.62(\mathrm{~s}, 2 \mathrm{H}, \mathrm{pz}), 7.94\left(\mathrm{~d}, 2 \mathrm{H},{ }^{3} \mathrm{~J}=16 \mathrm{~Hz}\right), 7.68-7.60(\mathrm{~m}, 4 \mathrm{H}, \mathrm{Ph}), 7.47-7.35(\mathrm{~m}, 6 \mathrm{H}, \mathrm{Ph}), 7.22$ $\left(\mathrm{d}, 2 \mathrm{H},{ }^{3} \mathrm{~J}=16 \mathrm{~Hz}\right)$ ppm. The IR and Raman spectra are enclosed below.

\section{Copies of NMR, IR and Raman spectra}

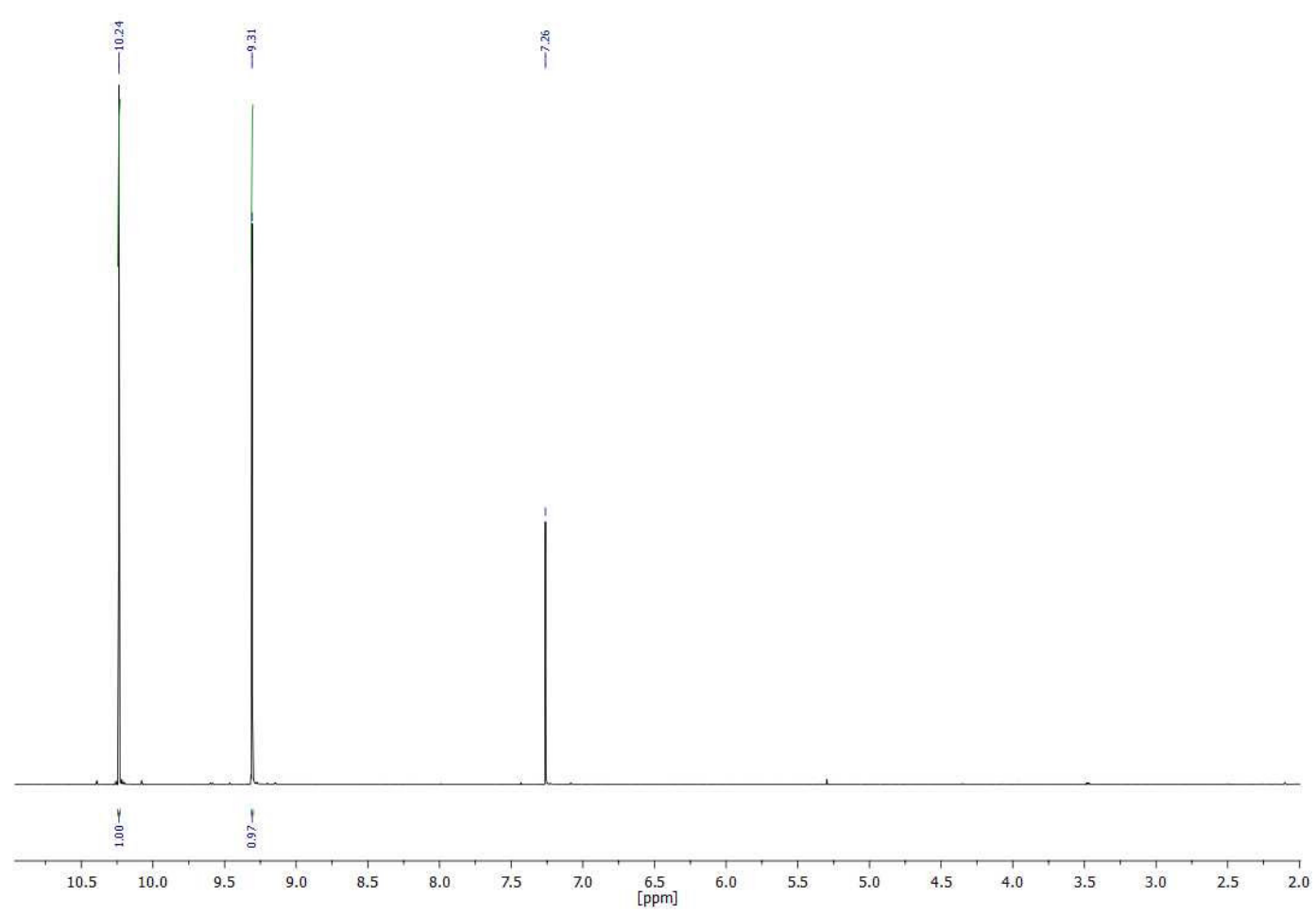

Figure S1. ${ }^{1} \mathrm{H}$ NMR spectrum of pyrazine-2,5-dicarbaldehyde (1) in $\mathrm{CDCl}_{3}(600 \mathrm{MHz})$. 


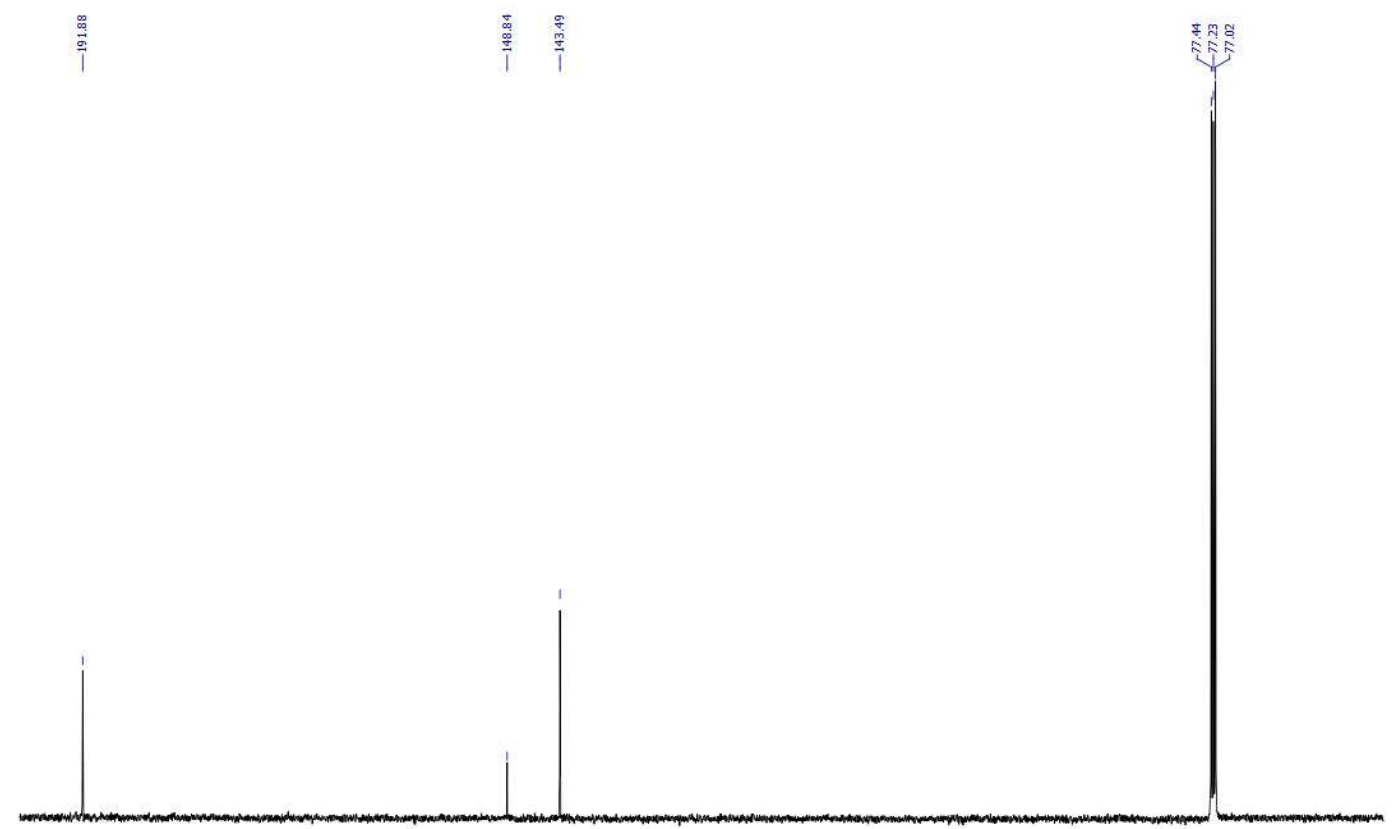

$\begin{array}{llllllllllllllllllllllllllll}195 & 190 & 185 & 180 & 175 & 170 & 165 & 160 & 155 & 150 & 145 & 140 & 135 & 130 & 125 & 120 & 115 & 110 & 105 & 100 & 95 & 90 & 85 & 80 & 75 & 70 & 65\end{array}$

Figure S2. ${ }^{13} \mathrm{C}$ NMR spectrum of pyrazine-2,5-dicarbaldehyde (1) in $\mathrm{CDCl}_{3}(150 \mathrm{MHz})$.

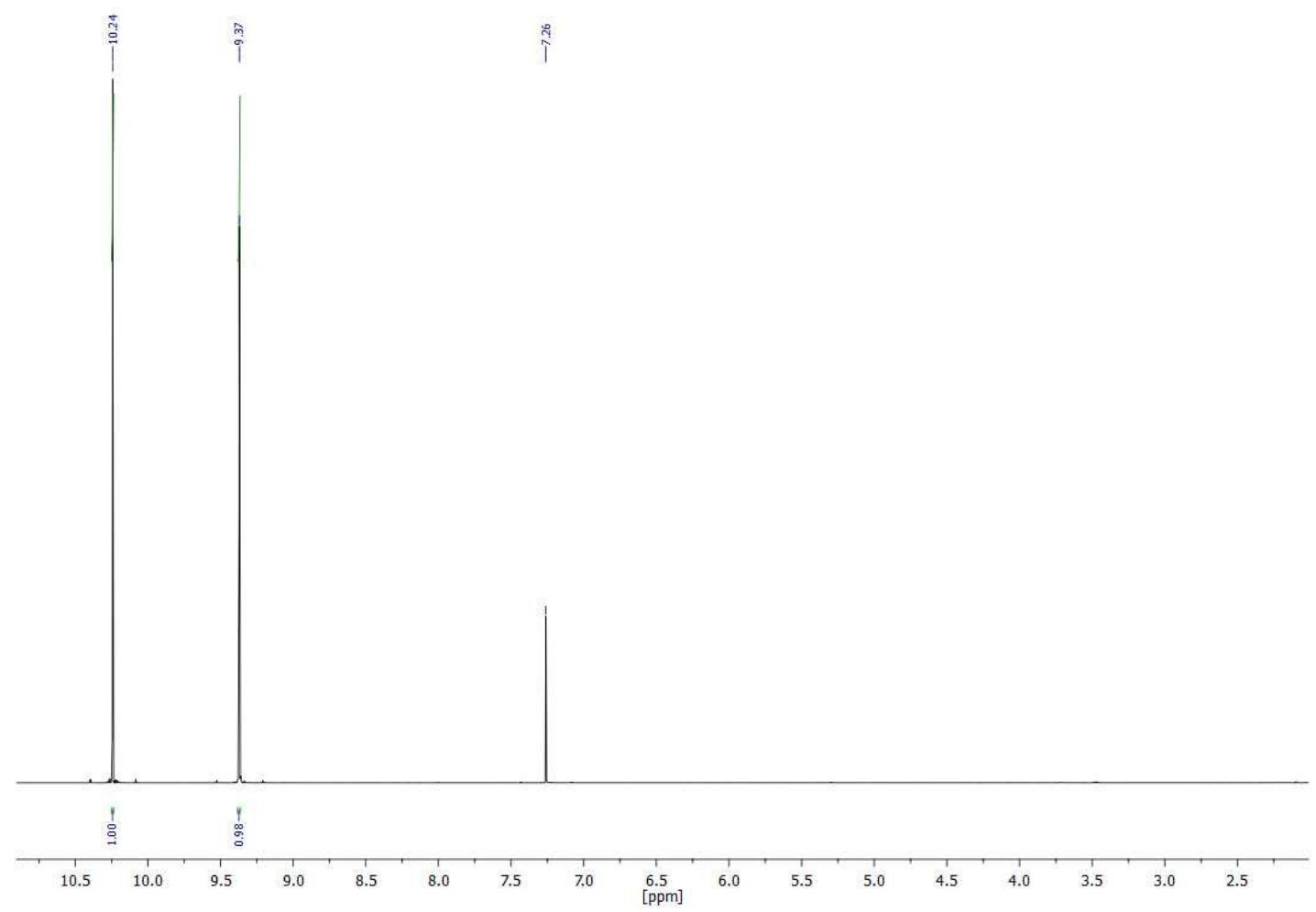

Figure S3. ${ }^{1} \mathrm{H}$ NMR spectrum of pyrazine-2,6-dicarbaldehyde (2) in $\mathrm{CDCl}_{3}(600 \mathrm{MHz})$. 


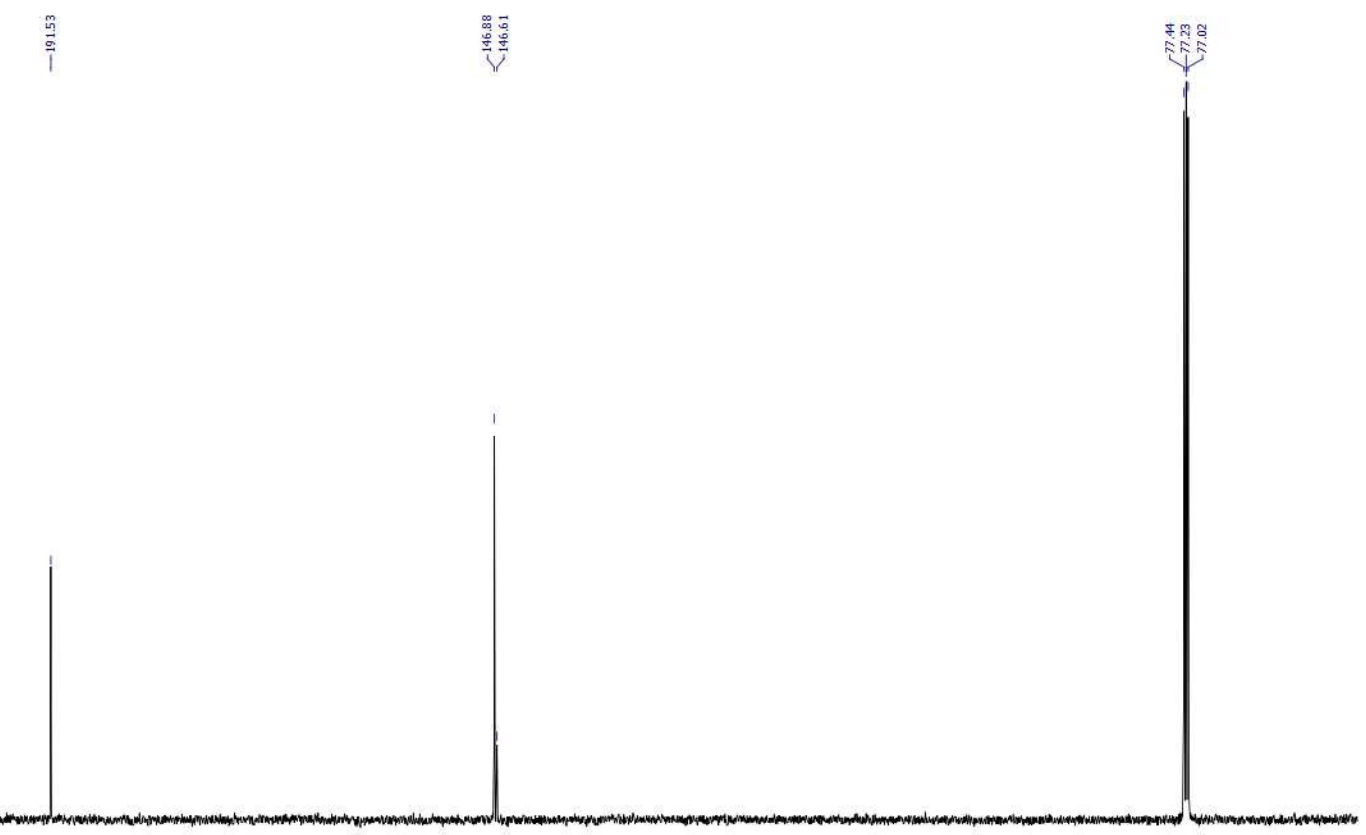

$\begin{array}{llllllllllllllllllllllllllll}195 & 190 & 185 & 180 & 175 & 170 & 165 & 160 & 155 & 150 & 145 & 140 & 135 & \left.\begin{array}{l}130 \\ {[\mathrm{ppm}]}\end{array}\right] & 125 & 120 & 115 & 110 & 105 & 100 & 95 & 90 & 85 & 80 & 75 & 70 & 65 & 60\end{array}$

Figure S4. ${ }^{13} \mathrm{C}$ NMR spectrum of pyrazine-2,6-dicarbaldehyde (2) in $\mathrm{CDCl}_{3}(150 \mathrm{MHz})$. 


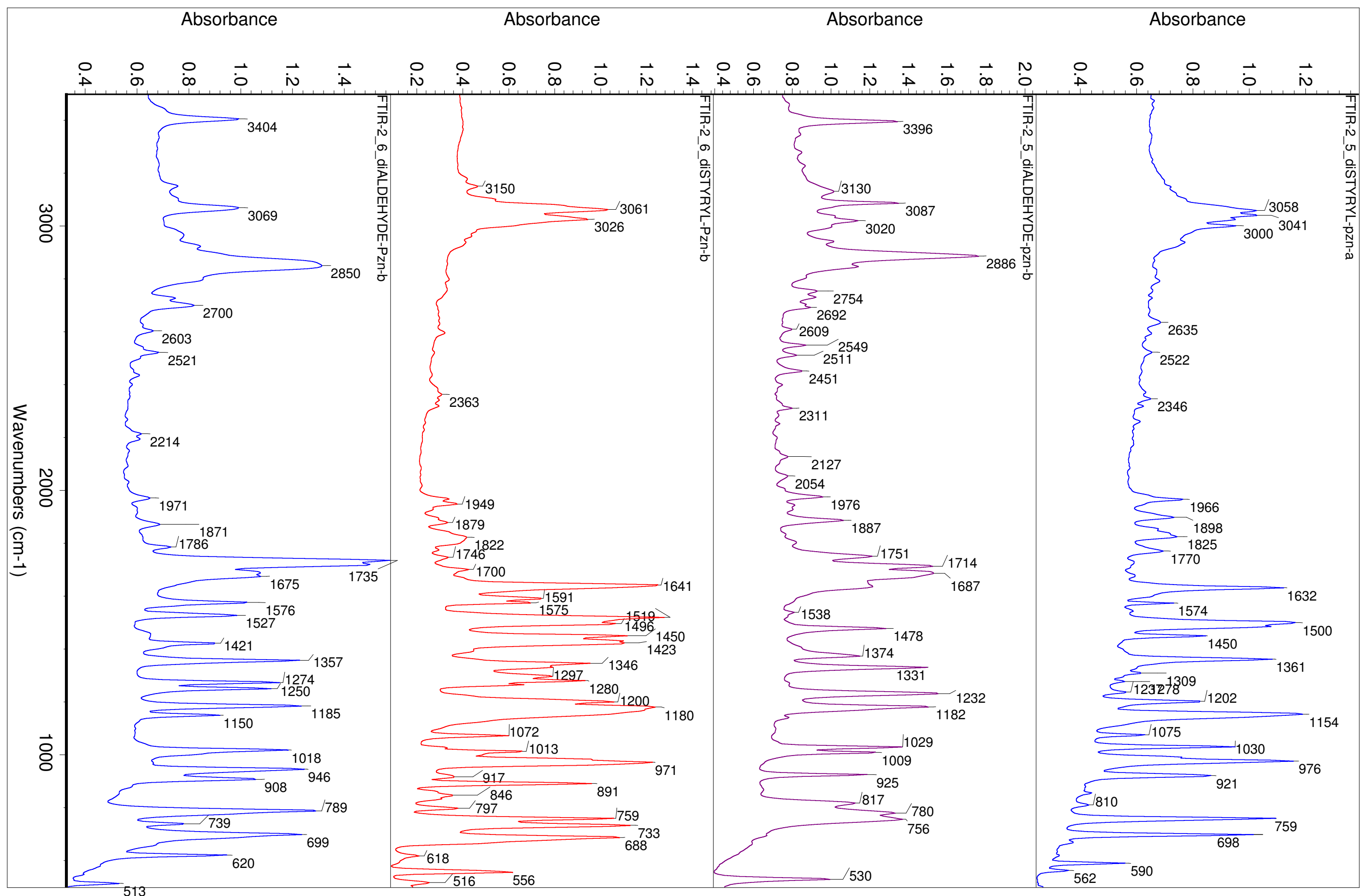




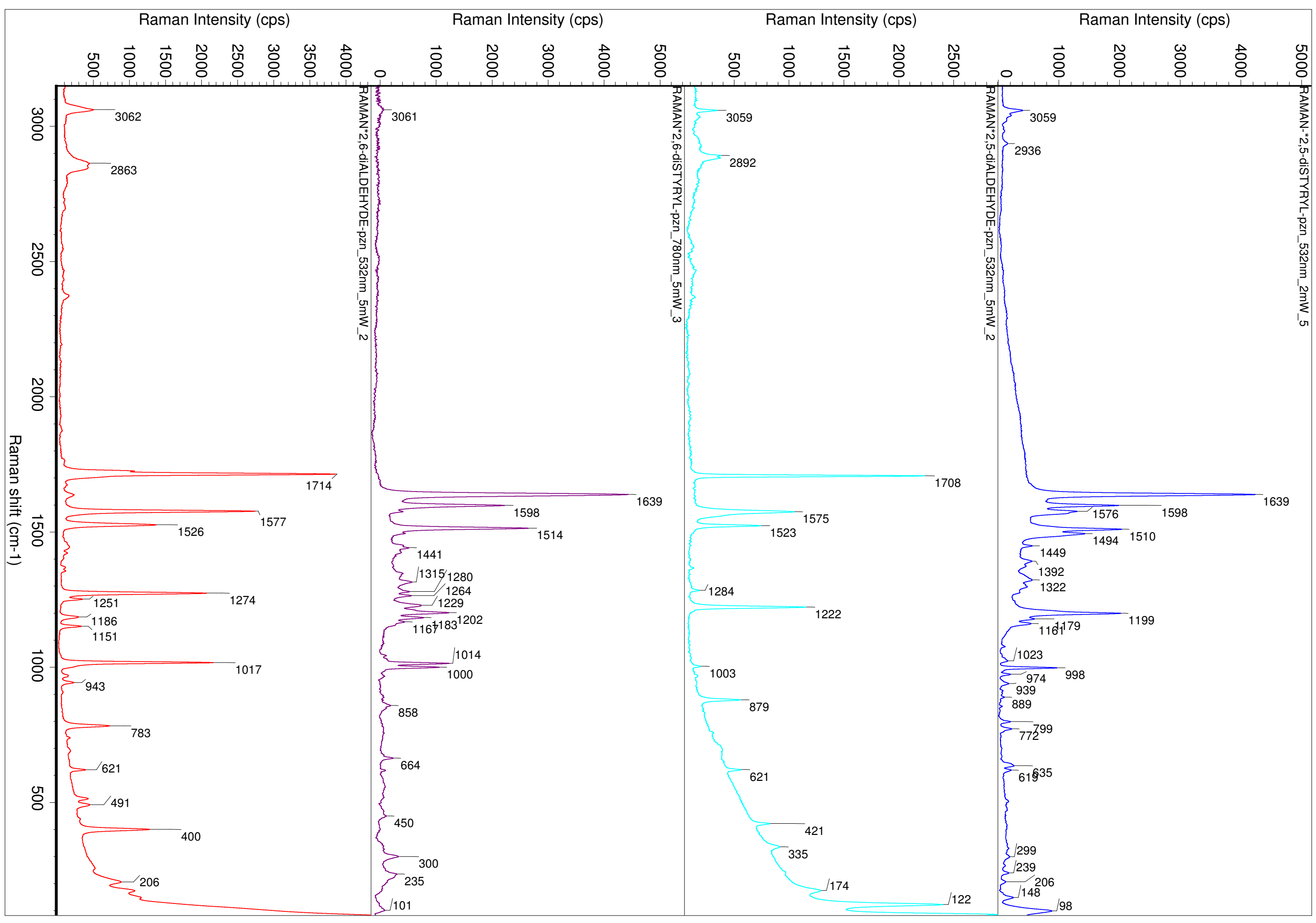




\section{X-ray structure data}

Single crystals of both $\mathbf{1}$ and 2 were grown via vacuum sublimation at $35{ }^{\circ} \mathrm{C}$. Single crystal of 11 was obtained by slow diffusion of hexane into the solution of the title compound in DCM.

Crystal data for 1 , Formula $\mathrm{C}_{6} \mathrm{H}_{4} \mathrm{~N}_{2} \mathrm{O}_{2}, M_{\mathrm{r}}=136.11$, Monoclinic, $P 2_{1} / c$ (No 14), $a=6.5900$ (16) $\AA$, $b=3.9718$ (10) $\AA, c=10.968$ (3) $\AA, \beta=100.709$ (12) $)^{\circ}, V=282.08$ (12) $\AA^{3}, Z=2$, $D_{\mathrm{x}}=1.603 \mathrm{Mg} \mathrm{m}^{-3}$, Temperature $=120 \mathrm{~K}$, colourless prism of dimensions $0.27 \times 0.11 \times 0.03$ $\mathrm{mm}$, multi-scan absorption correction $(\mu=0.13), T_{\min }=0.967, T_{\max }=0.996$; a total of 3180 measured reflections $\left(\theta_{\max }=26^{\circ}\right)$, from which 553 were unique $\left(R_{\text {int }}=0.053\right)$ and 409 observed according to the $I>2 \sigma(I)$ criterion. The refinement converged $\left(\Delta / \sigma_{\max }=0.001\right)$ to $R$ $=0.059$ for observed reflections and $w R\left(F^{2}\right)=0.172$, GOF $=1.17$ for 47 parameters and all 553 reflections. The final difference map displayed no peaks of chemical significance $\left(\Delta \rho_{\max }=0.43, \Delta \rho_{\min }=-0.32\right.$ e. $\left.\AA^{-3}\right)$. The structure was refined as non-merohedry twin, twin matrix : $100.223 ; 0-10 ; 00-1$; twin ratio 0.630:0.270.

Crystal data for 2, Formula $\mathrm{C}_{6} \mathrm{H}_{4} \mathrm{~N}_{2} \mathrm{O}_{2}, M_{\mathrm{r}}=136.11$, Orthorhombic, Pca2 1 (No 29), $a=$

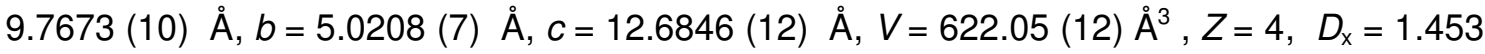
$\mathrm{Mg} \mathrm{m}^{-3}$, Temperature $=150 \mathrm{~K}$, colourless prism of dimensions $0.28 \times 0.28 \times 0.13 \mathrm{~mm}$, multiscan absorption correction $(\mu=0.11), T_{\min }=0.969, T_{\max }=0.986$; a total of 3748 measured reflections $\left(\theta_{\max }=27.5^{\circ}\right)$, from which 1397 were unique $\left(R_{\text {int }}=0.025\right)$ and 924 observed according to the $I>2 \sigma(I)$ criterion. The refinement converged $\left(\Delta / \sigma_{\max }=0.001\right)$ to $R=0.041$ for observed reflections and $w R\left(F^{2}\right)=0.104, G O F=1.04$ for 152 parameters and all 1397 reflections. Absolute structure was not determined: Flack parameter $=2(2)$. The final difference map displayed no peaks of chemical significance $\left(\Delta \rho_{\max }=0.13, \Delta \rho_{\min }=-0.11\right.$ e. $\AA^{-}$

$\left.{ }^{3}\right)$. The whole molecule is disordered into two positions, the ratio of occupancy factor is 0.69:0.31.

Crystal data for 11, $\mathrm{C}_{8} \mathrm{H}_{10} \mathrm{~N}_{2} \mathrm{O}_{4}, M_{\mathrm{r}}=198.18$, Monoclinic, $P 2_{1} / \mathrm{m} \quad$ (No 11), $a=6.1675$ (5) $\AA$, $b=6.3644$ (6) $\AA, c=11.5676(11) \AA, \beta=92.829(4)^{\circ}, \mathrm{V}=453.50$ (7) $\AA^{3}, Z=2, \quad D_{x}=$ $1.451 \mathrm{Mg} \mathrm{m}^{-3}$, Temperature $=150 \mathrm{~K}$, yellow plate of dimensions $0.39 \times 0.10 \times 0.06 \mathrm{~mm}$, multi-scans absorption correction $\left(\mu=0.12 \mathrm{~mm}^{-1}\right) T_{\min }=0.955, T_{\max }=0.993$; a total of 3178 
measured reflections $\left(\theta_{\max }=26^{\circ}\right)$, from which 977 were unique $\left(R_{\text {int }}=0.035\right)$ and 658 observed according to the $I>2 \sigma(I)$ criterion. The refinement converged $\left(\Delta / \sigma_{\max }=0.001\right)$ to $R$ $=0.044$ for observed reflections and $\mathrm{w} R\left(F^{2}\right)=0.113$, GOF $=1.03$ for 90 parameters and all 977 reflections. The final difference map displayed no peaks of chemical significance $\left(\Delta \rho_{\max }\right.$ $=0.26, \Delta \rho_{\min }=-0.25$ e. $\left.\AA^{-3}\right)$. The whole molecule is situated on the mirror of the space group with the exception of hydrogen atoms of methyl moieties, which consequently appears to be disordered.

Detailed crystallographic data for structural analysis have been deposited with the Cambridge Crystallographic Data Centre, CCDC no. 1004085, 1004086 and 972057 for 1, 2 and 11, respectively. Copies of this information may be obtained free of charge from The Director, CCDC, 12 Union Road, Cambridge CB2 1EY, UK (Fax: +44-1223336033; e-mail: deposit@ccdc.cam.ac.uk or www: http://www.ccdc.cam.ac.uk).

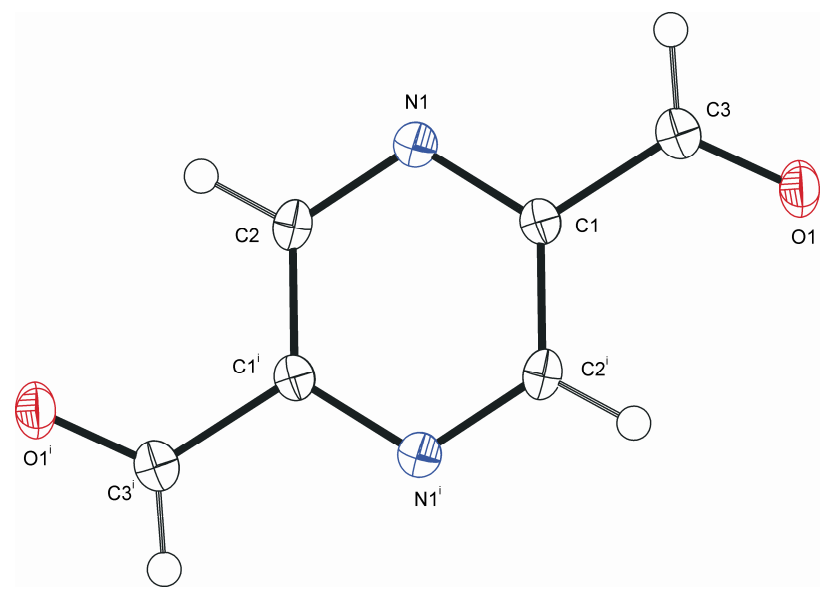

Figure S5. View on the molecular structure of 1. Displacement ellipsoids are drawn on $50 \%$ probability level. 


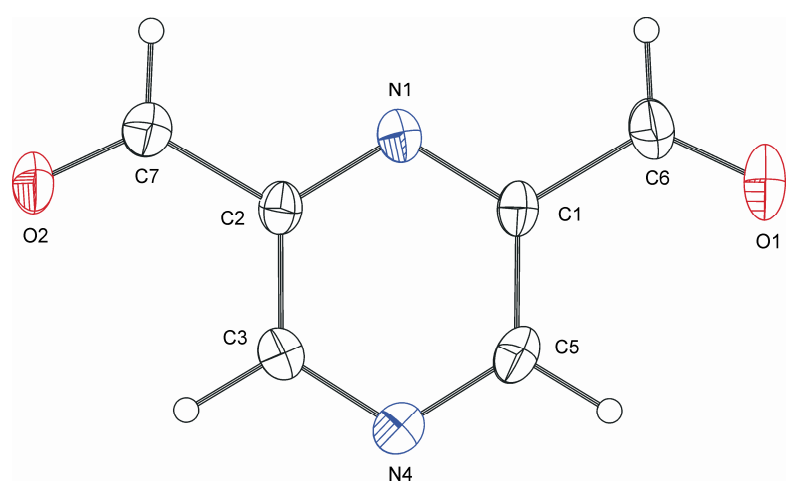

Figure S6. View on the molecular structure of 2. Displacement ellipsoids are drawn on 30\% probability level. Positions of disordered atoms with low occupancy (0.3) are omitted for clarity.

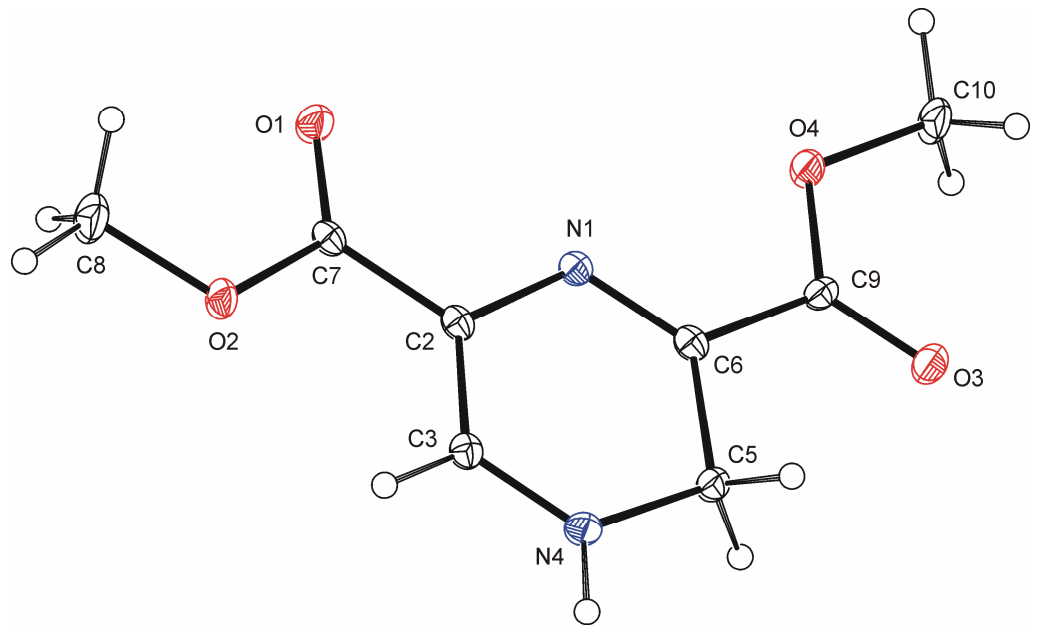

Figure S7. View on the molecular structure of 11. Displacement ellipsoids are drawn on $30 \%$ probability level. The disordered hydrogen atoms in methyl moieties are omitted for clarity.

\section{References}

[1] Sheldrick, G.M. Acta Crystallogr. Sect. A: Found. Crystallogr. 2008, 64, 112-122.

[2] Pray, A. R.; Heitmiller, R. F.; Strycker, S.; Aftandilian, V. D.; Muniyappan, T.; Choudhury, D.; Tamres, M. Inorg. Synth. 1990, 28, 321-323.

[3] Klingele, J.; Moubaraki, B.; Murray, K. S.; Boas, J. F.; Brooker, S. Eur. J. Inorg. Chem. 2005, 1530-1541. 
[4] Eiermann, U.; Krieger, C.; Neugebauer, F. A.; Staab, H.A. Chem. Ber. 1990, 123, 523-533.

[5] (a) Torf, S. F.; Khromov-Borisov, N. V. Zh. Obsch. Khim. 1960, 30, 1798-1805; (b) Chandrasekhar, S.; Sridhar, M. Tetrahedron Lett. 2000, 41, 5423-5425.

[6] Ellard, J. M.; Farthing, Ch. N.; Hall, A. PCT Int. Appl. 2011, WO 2011/009898 A1.

[7] Williams, J. R.; Cossey, J. J.; Adler, M. J. Org. Chem. 1972, 37, 2963-2965.

[8] Hasegawa, M.; Suzuki, Y.; Suzuki, F.; Nakanishi, H. J. Polym. Sci., Part A-1 1969, 7, 743-752. 